\title{
KESANTUNAN TUTURAN IMPERATIF SISWA SMK MUHAMMADIYAH 2 BANDUNG: KAJIAN PRAGMATIK
}

\author{
Rani Siti Fitriani \\ Uninus Bandung
}

\begin{abstract}
Abstrak
Makalah ini adalah penelitian kesantunan Imperatif Siswa SMK Muhammadiyah 2 Bandung: kajian pragmatik. Penelitian ini mendeskripsikan penanda imperatif dan wujud imperatif yang digunakan siswa dalam kesantunan imperatif. Metode yang digunakan dalam penelitian ini adalah metode deskriptif kualitatif. Teknik pengumpulan data yang digunakan dalam penelitian ini adalah teknik simak; teknik cakap; dan tes melengkapai wacana atau Discourse Completion Test (DCT) tipe C. Sampel data penelitian ini adalah responden yang terdiri dari 20 siswa perempuan dan 20 siswa laki-laki SMK Muhammadiyah 2 Bandung. Kajian teori yang digunakan dalam penelitian ini adalah skala kesantunan (Leech: 1983); skala kesantunan (Brown \& Levinson: 1987); kesantunan imperatif (Rahardi: 2005); tata baku bahasa Indonesia (Moeliono: 1992); dan Chaer \& Leonie (2004). Berdasarkan hasil penelitian ini, diketahui bahwa kesantunan imperatif dapat dilihat dri penanda imperatif dan wujud imperatif. Penanda imperatif terdiri daripenanda kesantunan; pronomina; interjeksi; dan verba. Wujud imperatif terdiri dari bentuk kalimat; strategi; dan campur kode atau alih kode.
\end{abstract}

Kata Kunci: Kesantunan imperatif, penanda imperatif, wujud imperatif, dan pragmatik

\begin{abstract}
These paper deals with a study on the realization of imperative politeness by student of SMK at Bandung city. The aim research to description imperative markers and shape of imperative was used as student in imperative politeness. The research was condusted under qualitative desription method. Data were called with attentively technique; conversation technique; and Tes Melengkapi Wacana or Discourse Completion Test Type C. The sample of data is respondence as 20 girls student and 20 boys student at SMK at Bandung city. The reference of the research are scala of politeness (Leech: 1983); scala of politeness (Brown \& Levinson: 1987); imperative politeness (Rahardi: 2005); gramatical of Indonesian language (Moeliono: 1992); and sosiolinguistics (Chaer \& Leonie: 2004).The research explained that imperative politeness can refer to imperative markers is to elaborate as sign of politeness; pronoun; interjections; and verba. The shape of imperaive is to elaborate as the type of sentence; strategies; and code mix or code position.
\end{abstract}

Keywords: imperative polittenes, imperative markers, form of imperative, and pragmatics 


\section{PENDAHULUAN}

Manusia diciptakan Allah Swt. sebagai makhluk sosial. Ia tidak dapat hidup sendiri karena harus bersosialisasi dengan orang lain. Sebagai makhluk sosial manusia hidup berkelompok baik dalam lingkungan paling kecil, seperti antaranggota keluarga, maupun di lingkungan yang paling besar seperti antarbangsa. Manusia menggunakan bahasa sebagai alat komunikasi dalam kehidupannya sehari-hari. Bahasa merupakan alat komunikasi yang ideal bagi manusia dalam menyampaikan perasaan, gagasan, dan keinginannya kepada orang lain.

Bahasa merupakan alat komunikasi antara penutur dan mitra tutur. Berkomunikasi merupakan bentuk interaksi yang melibatkan pengirim dan penerima informasi. Dengan bahasa penutur dap

at menyampaikan pendapat dan perasaannya kepada mitra tutur. Tarigan (2009: 134) berpendapat bahwa komunikasi mengandung maksud dan tujuan tertentu yang dirancang untuk menghasilkan beberapa efek pada lingkungan para penyimak dan para pembica.

Berdasarkan nilai komunikatifnya, bahasa dibedakan menjadi lima yakni (1) kalimat berita atau deklaratif, (2) kalimat perintah atau imperatif, (3) kalimat tanya atau interogatif, (4) kalimat seruan atau ekslamatif, dan (5) kalimat penegar atau emfatik (Moeliono, 1992: 337). Sesuai dengan sebutannya masing-masing kalimat memiliki fungsi yang berbeda. Misalnya, kalimat perintah digunakan untuk memberikan perintah. Rahardi (2004: 4) menyatakan bahwa tuturan yang berkontruksi imperatif itu digunakan untuk menyatakan maksud menyuruh.

Menurut Rahardi (2005: 87) tuturan imperatif memiliki wujud imperatif. Wujud imperatif tersebut mencakup dua hal, yakni (1) wujud imperatif formal atau struktural dan (2) wujud imperatif pragmatik atau nonstruktural. Wujud formal imperatif dalam bahasa Indonesia memiliki tiga ciri dasar, yakni (1) menggunakan intonasi, (2) kata kerja yang lazim digunakan adalah kata kerja dasar, dan (3) menggunakan partikel -lah. Rahardi (2005: 93) menyebutkan bahwa wujud imperatif pragmatik adalah realisasi maksud imperatif dalam bahasa Indonesia apabila dikaitkan dengan konteks situasi tutur yang melatarbelakanginya Artinya, setiap tuturan imperatif penutur memiliki maksud imperatif berupa strategi dalam tuturan imperatif.

Perhatikan ilustrasi berikut ini, tuturan yang mendeskripsikan wujud imperatif pragmatik menggambarkan strategi yang berbeda dalam kesantunan tuturan imperatif.

\begin{tabular}{|l|l|}
\hline$(1)$ & "Pinjem penghapus dong!" \\
\hline$(2)$ & $\begin{array}{l}\text { "Aduh uangku ketinggalan, padahal saya mau beli buku tulis. Em ... boleh pinjem } \\
\text { uang kamu dulu nggak ya?" }\end{array}$ \\
\hline$(3)$ & $\begin{array}{l}\text { "Perutku lapar sekali, kalau ada seseorang yang memberiku makanan, tentu aku } \\
\text { tidak akan menolaknya." }\end{array}$ \\
\hline
\end{tabular}

Berdasarkan ilustrasi di atas diketahui bahwa kalimat perintah atau disebut juga tuturan imperatif tidak hanya berbentuk kalimat perintah saja tetapi dapat diungkapkan dengan bentuk kalimat interogatif atau deklaratif. 
Rahardi (2005: 73) berpendapat bahwa tindak tutur permohonan dalam hal ini permohonan antarperempuan dan antarlaki-laki pun berbeda. Perempuan lebih cenderung menggunakan bahasa yang mengandung unsur ketidaklangsungan, sedangkan pada lakilaki akan menggunakan permohonan yang langsung dan terus terang. Jadi, Perempuan akan menggunakan permohonan yang samar dan tidak langsung. Perhatikan ilustrasi tuturan imperatif siswa perempuan dan siswa laki-laki kepada temannya atau mitra tuturnya berikut ini.

\begin{tabular}{|l|l|}
\hline (4) & "Maaf ... say ... pang bawain bukulah di lemari yang di depan kelas ... \\
\hline & Konteks \\
& $\begin{array}{l}\text { Tuturan penutur siswa perempuan (R-2) ketika meminta bantuan mitra tutur agar } \\
\text { membawakan buku untuk penutur. Peristiwa tuturan terjadi di dalam kelas ketika } \\
\text { pelajaran berlangsung dan siswa diberitugas kelompok oleh guru. }\end{array}$ \\
&
\end{tabular}

Kesantunan di dalam tuturan imperatif sangat penting dilakukan oleh penutur untuk menghargai mitra tutur. Secara linguistik, kesantunan dalam pemakaian tuturan imperatif bahasa Indonesia sangat ditentukan oleh muncul atau tidak munculnya ungkapan-ungkapan penanda kesantunan.

Untuk menilai santun tidaknya sebuah tuturan dapat digunakan skala ketidaklangsungan Leech dan muncul atau tidaknya ungkapan penanda kesantunan seperti yang dikemukakan oleh Rahardi. Skala ketidaklangsungan Leech (dalam Rahardi, 2005: 67) menunjuk kepada peringkat langsung atau tidaknya sebuah tuturan. Semakin suatu tuturan bersifat langsung, maka semakin dianggap tidak santunlah tuturan itu dan semakin suatu tuturan bersifat tidak langsung maka semakin dianggap santunlah tuturan itu. Kesantunan dalam tuturan imperative sangat ditentukan oleh muncul tidaknya ungkapan-ungkapan penanda kesantunan seperti maaf, tolong, coba, mohon, dan sebagainya. Namun, dalam kenyataannya tidak semua penutur menggunakan penanda kesantunan tersebut dalam tuturan imperatifnya kepada mitra tutur.

Kesantunan dalam suatu interaksi merupakan alatyang digunakan untukmenunjukkan kesadaran tentang wajah orang lain. Wajah merupakan wujud pribadi seseorang dalam masyarakat. Hal ini bergantung pada seberapa dekat atau jauhnya hubungan sosial yang dimiliki antara penutur dan mitra tutur. (Yule, 2006: 104). Jadi, semakin penutur berusaha menghargai mitra tutur dengan cara bertutur yang santun maka semakin memperlihatkan 'wajahnya' yang berkepribadian santun. Sebalinya ketika penutur kurang menghargai mitra tutur dengan cara berbahasa yang kurang santun maka semakin memperlihatkan 'wajahnya; yang berkepribadian kurang santun.

Berdasarkan realisasi tuturan imperatif dalam bahasa Indonesia yang beragam, penelitian ini dilakukan untuk mengungkapan penanda kesantunan imperatif meliputi penanda imperatif dan wujud imperatif. Metode yang digunakan adalah meode deskriptif dengan pengumpulan populasi dan sampel data mengacu pada penelitian yangtelah dilakukan Aziz (2003) mengenai Tes Melengkapi Wacana berupa Discourse Completion Test (DCT) tipe C. Teknik tersebut dijadikan proyek CCSARP (Cross-cultural Speech Act Realization Project) oleh Blum Kulka (1989).

Dalam penelitian ini penulis menggunakan teknik penyediaan data dengan sebuah percakapan sehingga terjadi kontak antara penulis sebagai peneliti dan responden sebagai 
narasumber. Langkah pertama, penulis melakukan teknik dasar-teknik pancing yaitu memancing responden dengan memberikan beragam contoh tuturan imperatif sehingga responde memahami bagaiman tuturan kalimat imperatif. Kemudian teknik lanjutan I-teknik cakap semuka dilakukan agar responden diarahkan untuk membuat kalimat imperatif yang dibutuhkan untuk data penelitian ini tentang kesantunan imperatif dalam bahasa Indonesia. Selanjutnya teknik lanjutan II-teknik catat dengan cara membagikan angket isian DCT tipe C. Angket isian ini dibuat dalam bentuk permintaan kepada responden untuk mengisi bagian tertentu yang khusus dikososngkan setelah sebelumnya ada wacana yang mendeskripsikan sebuah konteks atau situasi. Bentuk DCT tipe C lebih terbuka karena responden dapat mengisi angket dengan tuturan yang alami tanpa arahan dan paksaan.

\section{KESANTUNAN IMPERATIF}

Peristiwan tuturan akan berlangsung harmonis ketika penutur dan mitra tutur memperhatikan kesantunan dalam berbahasa. Dengan demikian, di antara penutur dan mitra tutur terjalin kerja sama yang baik dengan bentuk saling menghomati antara yang satu dengan yang lainnya. Tindak tutur penutur yang baik meliputi bahasa lisan dan bahasa tubuh yang menyenangkan mitra tuturnya.

Skala kesantunan yang dikemukakan Leech (1983: 206-207) berkaitan dengan berikut ini.

(1) Cost-Benefit Scale atau skala keuntungan

Penutur yang bijaksana dalam bertutur akan mengurangi keuntungan bagi dirinya dan lebih memaksimalkan keuntungan bagi mitra tuturnya. Semakin tuturan itu merugikan penutur maka semakin santun dan bijaksana tuturannya.

(2) Optionality scale atau skala pilihan

Penutur yang dermawan akan memberikan pilihan kepada mitra tutur misalnya ketika menyuruh. Dengan adanya pilihan maka tuturan akan lebih santun dibandingkan tidak memberika pilihan.

(3) Inderctness scale atau skala ketidaklangsungan

Kalimat imperatif yang dituturkan secara tidak langsung lebih santun dibandingkan dengan tuturan imperatif langsung. Misalnya, tuturan imperatif dengan bentuk kalimat interogatif atau deklaratif.

(4) Authority scale atau skala keotoritasan

Keotoritasan berkaitan dengan status sosial (rank rating) antara penutur dengan mitra tutur. Semakin jauh jarak sosial maka penutur akan menggunakan tuturan yang lebih santun kepada mitra tutur. Sebaliknya ketika jarak sosial semakin dekat maka semakin santai tuturan penutur kepada mitra tutur.

(5) Social distance scala atau skala jarak sosial

Hubungan jarak sosial antara penutur dan mitra tutur sangat memengaruhi tuturan. Semakin dekat jarak sosial antara penutur dan mitra tutur maka akan tuturannya akan lebih santai karena hubungan mereka akrab sehingga dianggap santun. Namun, apabila jarak sosialnya semakin jauh maka tuturan penutur aka lebih santun untuk menghargai mitra tutur.

Skala kesantunan menurut Brown dan levinson (1987: 74) terdiri dari tiga.

(1) sosial distance between speaker and hearer atau skala peringkat jarak sosial antara 
penutur dan mitra tutur. Skala ini banyak dipengaruhi oleh latar belakang usia, jenis kelamin, dan latar sosialkultural.

(2) the speaker and hearer relative power atau skala peringkat status sosial antara penutur dan mitra tutur atau disebut juga peringkat kekuasaan (power rating). Skala ini dipengaruhi oleh latar jabatan, kedudukan, golongan, dan profesi.

(3) The degree of imposition associated with the required expenditure of goods or services atau skala peringkat tindak tutur atau disebut juga rangk rating. Skala ini berkaitan dengan situasi atau konteks tuturan berlangsung.

Penggunaan jenis bentuk kalimat sangat mempengaruhi tingkat kesantunan tuturan imperatif. Menurut Rahardi (2005: 134) tuturan imperatif berbentuk kalimat imperatif memiliki tingkat kesantunan lebih rendah dibandingkan dengan tuturan imperatif yang berbentuk kalimat deklaratif dan interogatif karena memiliki unsur ketidaklangsungan yang tinggi. Tuturan imperatif dikelompokkan menjadi tiga jenis.

(1) Bentuk kalimat imperatif, memiliki tingkat kesantunan yang rendah dan ketidaklangsung yang tinggi, misalnya "Tolong ambilkan buku itu!";

(2) Bentuk kalimat interogatif, memiliki tingkat kesantunan yang sedang dengan ketidaklangsungan sedang, misalnya "Maukah kau mengantarku pulang?"; dan

(3) Bentuk kalimat deklaratif, memiliki tingkat kesantunan yang tinggi dan ketidaklangsungan yang rendah, "Wah dompetku ketingggalan padahal aku belum bayar batagor." Maksud dari tuturan ini agar temannya mau meminjamkan uang atau membayarkan dulu.

Rahardi (2005: 93-116) mengelompokkan strategi kesantunan imperatif menjadi beberapa macam berdasarkan tingkat kesatunan yaitu tuturan yang mengandung pragmatik imperatif perintah; suruhan; permintaan; permohonan; desakan; bujukan; imbauan; persilaan; ajakan; izin; mengizinkan; larangan; harapan; umpatan; pemberian ucapan selamat; anjuran; dan ngelulu. Strategi yang tepat dan baik akan memengaruhi kesantunan tuturan impearatif.

Dalam tuturan kerapkali terjadi campur kode atau alih kode karena latar belakang sosial budaya yang berbeda. Selain itu, tujuan untuk menciptakan hubungan yang akrab sehingga jarak sosial semakin dekat serta membuat suasana menjadi lebih santai dan tidak formal menjadi salah satu alasan penutur atau mitra tutur bertutur campu kode dan alih kode. Menurut Chaer \& Leonie (2004: 106-114) campur kode merupakan peristiwa tuturan ketika penutur danmitra tutur menggunakan dua tau lebih jenis bahasa (bisa bilingual atau multilingual) dalam bertutur. Penyebab campur kode dan alih kode adalah penutur; mitra tutur; orang ketiga; perubahan situasi formal ke nonformal; dan perubahan topik pembicaraan.

Dalam tuturan penggunaan pronomina atau kata ganti orang sangat memengaruhi bentuk kesantunan atau hubungan keakraban antara penutur dan mitra tutur. Moeliono (1992: 173) berpendapat bahwa persona pertama kau lebih banyak dipakai dalam pembicaraan batin pada situasi yang tidak formal dan yang lebih banyak menunjukkan keakraban antara pembicara dengan pendengar. Pronomina saya lebih sering digunakan dalam situasi formal atau tulisan dan ujaranyang resmi.

Interjeksi atau kata seru merupakan kata tugas yang mengungkapkan rasa hati manusia. Penggunaan interjeksi dapat menciptakan hubungan yang akrab dan memperkecil 
jarak sosial antara penutur dan mitra tutur. Oleh karena itu, penanda interjeksi dapat memengaruhi kesantunan tuturan imperatif.

\section{PEMBAHASAN}

Penulis menganalisis kesantunan tuturan imperatif berdasarkan penanda imperatif dan wujud imperatif yang dijelaskan sebagai berikut.

\section{a. Penanda Imperatif}

Perihal kesantunan tuturan imperatif dapat digambarkan dari penanda imperatif yang digunakan penutur.

\section{Penanda Kesantunan}

Berdasarkan realisasi data (6), (7), (8), dan (9) penanda kesantunan yang digunakan dalam kesantunan kalimat imperatif sangat beragam. Pada contoh (6) digunakan kata tolonglah, contoh (7) digunakan maaf, contoh (7) tidak menggunakan penanda kesantunan $(\varnothing)$, dan contoh (9) digunakan maaf dan tolong. Penanda kesantunan yang paling santun dituturkan oleh (RSLL3-170) kemudian (RPS6-23), (RSLL3-170), dan (RSP8-75)

\begin{tabular}{|l|l|}
\hline (5) & $\begin{array}{l}\text { "Tolonglah anterin aku pulang! soalnya aku lagi nggak enak badan!" } \\
\text { (RSLL4-121) } \\
\text { Penutur laki-laki dan mitra tutur laki-laki }\end{array}$ \\
\hline$(6)$ & $\begin{array}{l}\text { "Ning maaf anterin aku pulang dong! Aku nggak kuat kalau harus jalan. Ntar } \\
\text { uang bensinya aku ganti." } \\
\text { (RPS6-23) } \\
\text { Responden siswa perempuan dan siswa mitra tutur perempuan }\end{array}$ \\
\hline (7) & $\begin{array}{l}\text { "Ka anterin aku pulang yuk! Aku sakit trus mau pulang!" } \\
\text { (RSP8-75) } \\
\text { Responden siswa perempuan dan mitra tutur siswa laki-laki }\end{array}$ \\
\hline (8) & $\begin{array}{l}\text { "Nis, maaf bisa tolong antarkan saya pulang memakai motor kamu? Saya takut } \\
\text { pingsan di jalan." } \\
\text { (RSLL3-170) } \\
\text { Responden siswa laki-laki dan mitra tutur siswa perempuan }\end{array}$ \\
\hline $\begin{array}{l}\text { Konteks-Situasi 1 } \\
\text { Saat belajar di kelas Anda merasa demam sehingg guru menyuruh pulang. } \\
\text { Dalam kondisi seperti ini Anda tak mungkin pulang berjalan kaki seperti bi- } \\
\text { asa dan ingin meminta tolong kepada teman sekelas. Tuturan apa yang akan } \\
\text { Anda katakan kepada teman yang dimintai tolong... }\end{array}$
\end{tabular}

\section{Penanda Pronomina}

Berdasarkan realisasi data (10), (11), (12), dan (13) penanda pronomina atau kata sapaan dalam kesantunan imperatif sangat beragam. Pada contoh (10) digunakan kata sapaan bos; contoh (11) digunakan nama mitra tutur Indra, contoh (12) digunakan nama pendek mitra tutur, dan contoh (12) digunakan kata sapaan bro. Penanda kesantunan yang paling santun dituturkan oleh (RSP7-204) yang 
menguntungkan mitra tutur dengan kata sapaan bos seolah-olah mitra tutur lebih tinggi status sosialnya dari penutur padahal kenyataanya penutur dan mitra tutur sama-sama siswa sekelas. Kemudian penutur (RPS673) dan (RSP9-56) menggunakan kata sapaan nama mitra tutur untuk menciptakan hubungan yang akrab tidak ada jarak sosial sedangkan (RSLL10-157) menggunakan kata sapaan bro agar mitra tutur merasa senang dan akrab.

\begin{tabular}{|l|l|}
\hline$(10)$ & $\begin{array}{l}\text { "BoS, pinjamkan saya uang dulu, soalnya dompet tertinggal di kelas." } \\
\text { (RSP7-204) } \\
\text { Penutur siswa laki-laki dan mitra tutur siswa perempuan } \\
\text { "Indra, mau anterin aku pulang yuk, aku gak kuat untuk pulang sendiri." } \\
\text { (RSP6-73) } \\
\text { Responden siswa perempuan dan mitra tutur siswa laki-laki }\end{array}$ \\
\hline$(12)$ & $\begin{array}{l}\text { "Ka, boleh pinjem uang kamu dulu gak?" } \\
\text { (RSP9-56) } \\
\text { Penutur siswa perempuan dan mitra tutur siswa perempuan }\end{array}$ \\
\hline (13) & $\begin{array}{l}\text { "Bro, uangku habis nih, boleh pinjam uang ya?" } \\
\text { Penutur siswa laki-laki dengan mitra tutur siswa laki-laki }\end{array}$ \\
\hline $\begin{array}{l}\text { Konteks-Situasi } 4 \\
\text { Pada jam istirahat seperti biasa Anda jajan di kantin sekolah. Saat akan mem- } \\
\text { bayar makanan ternyata dompet Anda tertinggal di kelas. Anda ingin mem- } \\
\text { inta bantuan teman agar membayarkan dulu. Tuturan apa yang akan Anda } \\
\text { katakan kepada teman yang dimintai tolong ... }\end{array}$ \\
\hline
\end{tabular}

\section{Penanda Interjeksi}

Berdasarkan realisasi data (14), (15), (16), dan (17) penanda interjeksi dalam kesantunan imperatif sangat beragam. Pada contoh (14) dan (16) digunakan dong; contoh (15) digunakan nih dan teh, dan contoh (17) digunakan nih. Penutur (RPS6-33) dan (RSLL10-137) sama-sama menggunakan penanda interjeksi dong dengan mitra tutur yang sama jenis kelaminnya . Responden perempuan (RSLL10-137) dengan mira tutur laki-laki menggunakan penanda interjeksi nih dan teh sedangkan responden laki-laki (RSLL5-182) dengan mitra tutur perempuan menggunakan nih. Ragam pemakaian interjeksi dalam tuturan imperatif mendeskripsikan hubungan yang akrab antara penutur dan mitra tutur. Semakin akrab maka semakin santai ragam bahasa yag digunakan.

\begin{tabular}{|l|l|}
\hline$(14)$ & $\begin{array}{l}\text { "Pinjem pulpen dong, pulpen aku habis!" } \\
\text { (RSP6-33) } \\
\text { Penutur siswa perempuan dengan mitra tutur siswa perempuan }\end{array}$ \\
\hline$(15)$ & $\begin{array}{l}\text { "Yan, kamu punya pulpen 2 gak? Pulpenku tintanya habis nih, lupa mau beli } \\
\text { teh. Boleh gak aku pinjem sama kamu?" } \\
\text { (RSP2-79) } \\
\text { Penutur siswa perempuan dengan mitra tutur siswa laki-laki }\end{array}$ \\
\hline
\end{tabular}




\begin{tabular}{|l|l|}
\hline (16) & $\begin{array}{l}\text { "Pinjem pulpen dong, pulpen aku habis!" } \\
\text { (RSLL10-137) } \\
\text { Penutur siswa laki-laki dengan mitra tutur siswa laki-laki }\end{array}$ \\
\hline (17) & $\begin{array}{l}\text { Tian, kebeneran pulpen aku habis nih, kamu bawa pulpen berapa? Boleh } \\
\text { minjem gak?" } \\
\text { (RSLL5-182) } \\
\text { Penutur siswa laki-laki dengan mitra tutur siswa perempuan }\end{array}$ \\
& $\begin{array}{l}\text { Konteks-Situasi } 2 \\
\text { Anda sedang melaksanakan ulangan di kelas. Tiba-tiba pulpen yang digu- } \\
\text { nakan habis tintanya. Anda ingin meminjam kepada teman karena kalau } \\
\text { membeli ke koperasi khawatir lama dan waktu untuk menyelesaikan ujian } \\
\text { terganggu. Tuturan apa yang akan Anda katakan kepada teman yang dimintai } \\
\text { tolong ... }\end{array}$ \\
\hline
\end{tabular}

\section{Penanda Verba}

Ragam pengunaan verba yang digunakan dalam kesantunan imperatif dideskrisikan dalam data verba bersufiks -kan dan -in (sufiks bahasa Sunda). Pada contoh (18) tuturan (RSP3-40), tuturan (RSP3-40) contoh (19), dan tuturan (RSLL9196) contoh (21) digunakan verba ambilkan sedangkan contoh (20) tuturan (RSP6-93) digunakan verba ambilin. Penanda verba pada penanda imperatif untuk mempertegas bahwa tuturan responden adalah kalimat imperatif yang meminta mitra tutur melakukan apa yang diinginkan oleh penutur.

\begin{tabular}{|c|c|}
\hline (18) & $\begin{array}{l}\text { "Tolong ambilkan buku itu!" } \\
\text { (RSP3-40) } \\
\text { Responden siswa perempuan dengan mitra tutur siswa perempuan }\end{array}$ \\
\hline (19) & $\begin{array}{l}\text { "Indra bantuin dong, ambilin buku di lemari sana, pease help me." } \\
\text { (RSP6-93) } \\
\text { Responden siswa perempuan dengan mitra tutur siswa laki-laki }\end{array}$ \\
\hline (20) & $\begin{array}{l}\text { "Mad, tolong ambilkan buku yang ada di lemari itu!" } \\
\text { (RSLL3-140) } \\
\text { Responden siswa laki-laki dengan mitra tutur siswa laki-laki }\end{array}$ \\
\hline$(21)$ & $\begin{array}{l}\text { "Hey Neng, maaf bisa tolong ambilkan buku yang ada di lemari bentar, naaf } \\
\text { yang ngerepotin. } \\
\text { (RSLL9-196) } \\
\text { Responden siswa laki-laki dengan mitra tutur siswa perempuan }\end{array}$ \\
\hline & $\begin{array}{l}\text { Konteks-Situasi } 3 \\
\text { Anda mendapat tugas menjadi notulis dalam belajar kelompok yang diadakan } \\
\text { di kelas. Saat itu Anda membutuhkan buku sebagai referensi dan ingin mem- } \\
\text { inta tolong kepada teman sekelompok. Tuturan apa yang akan Anda katakan } \\
\text { kepada teman yang dimintai tolong... }\end{array}$ \\
\hline
\end{tabular}

\section{b. Wujud Imperatif}

Kesantunan tuturan imperatif penelitian ini dianalisis dari wujud imperatif. Wujud 
imperatif dibagi menjadi tiga macam.

\section{Bentuk Kalimat}

Ragam bentukkalimatyang digunakan dalam kesantunan imperatifdideskripsikan dalam data tuturan (RSP1-58) contoh (22) dengan bentuk kalimat interogatif, tuturan (RSP6-113) contoh (23) dengan bentuk kalimat imperatif-deklaratif, tuturan (RSLL10167) contoh (24) dengan bentuk kalimat imperatif, dan tuturan (RSLL4-221)

contoh (25) dengan bentuk kalimat interogatif-deklaratif. Berdasarkan bentuk yang digunakan dalam tuturan imperatif tuturan yang paling santun adalah (RSLL4221) kemudian tuturan (RSP1-58); selanjutnya tuturan (RSP6-113); dan yang terakhir tuturan (RSLL10-167).

\begin{tabular}{|l|l|}
\hline (22) & $\begin{array}{l}\text { "Bisakah kau mengantarku ke warnet?" } \\
\text { (RSP1-58) } \\
\text { Responden siswa perempuan dengan mitra tutur siswa perempuan }\end{array}$ \\
\hline (23) & $\begin{array}{l}\text { "Indra temenin aku ke warnet yu, aku mau ngerjain tugas nih, komputer aku } \\
\text { lagi rusak nih." } \\
\text { (RSP6-113) } \\
\text { Responden siswa perempuan dengan mitra tutur siswa laki-laki }\end{array}$ \\
\hline$(24)$ & $\begin{array}{l}\text { "Bro, kita kerjakan tugas di warnet yu!" } \\
\text { (RSLL10-167) } \\
\text { Responden siswa laki-laki dengan mitra tutur siswa laki-laki }\end{array}$ \\
\hline (25) & $\begin{array}{l}\text { "Vi, bisa nganter ke warnet sebelah gak? Soalnya komputer di rumah lagi } \\
\text { (RSLL4-221) } \\
\text { Responden siswa laki-laki dengan mitra tutur siswa perempuan }\end{array}$ \\
& $\begin{array}{l}\text { Konteks-Situasi } 5 \\
\text { Anda mendapat tugas dari guru di sekolah. Untuk mencari data dan me- } \\
\text { nyelesaikan tugas tersebut Anda harus pergi ke warnet karena komputer di } \\
\text { rumah rusak dan ingin meminta tolong kepada teman untuk menemani ke } \\
\text { warnet. Tuturan apa yang akan Anda katakan kepada teman yang dimintai } \\
\text { tolong ... }\end{array}$ \\
\hline
\end{tabular}

\section{Strategi}

Setiap tuturan imperatif memiliki suatu strategi yang berhubungan dengan bentuk kalimat yang digunakan penutur. Ragam strategi dalam kalimat imperatif merupaka salah satu wujud dari penanda kesantunan imperatif. Strategi kesantunan imperatif tuturan (RSP10-57) pada contoh 26 dan tuturan (RSLL10-157) contoh 28 adalah pernyataan (PYT) dan pertanyaan (PTY). Tuturan (RSP1-98) contoh 27 menggunakan strategi pertanyaan (PTY); pertanyaan (PTY); dan pernyataan (PYT) sedangkan tuturan (RSLL10-207) contoh 29 menggunakan strategi permintaan (PMT); alasan (ALS); dan bujukan (BJK).

Berdasarkan strategi yang digunakan maka tuturan imperatif yang tidak 
langsung menjadi kalimat tuturan yang lebih santun dibandingkan tuturan imperatif yang langsung. Tingkat kesantunan berdasarkan srategi yang digunakan adalah tuturan (RSP1-98); (RSLL10-157) dan (RSP10-57); dan terakhir (RSP10-57).

\begin{tabular}{|l|l|}
\hline (26) & $\begin{array}{l}\text { "Ya ampun ... uang aku ketinggalan. Dun, boleh minjem uang kamu dulu gak? } \\
\text { Kalau aku ngambil dulu pasti keburu masuk." } \\
\text { (RSP10-57) } \\
\text { Responden siswa perempuan dengan mitra tutur siswa perempuan }\end{array}$ \\
\hline (27) & $\begin{array}{l}\text { "Riko, kamu bawa uang lebih gak? Boleh pinjam? Soalnya dompet aku ket- } \\
\text { inggalan di kelas, ntar aku ganti." } \\
\text { (RSP1-98) } \\
\text { Responden siswa perempuan dengan mitra tutur siswa laki-laki }\end{array}$ \\
\hline (28) & $\begin{array}{l}\text { "Bro, uangku habis nih, boleh pinjam uang ya?" } \\
\text { Responden siswa laki-laki dengan mitra tutur siswa laki-laki }\end{array}$ \\
\hline (29) & $\begin{array}{l}\text { "Eh, pinjem dulu uang kamu dong! Dompet saya ketinggalan di tas, entar kalo } \\
\text { udah masuk kelas, saya ganti." } \\
\text { (RSLL10-207) } \\
\text { Responden siswa laki-laki dengan mitra tutur siswa perempuan }\end{array}$ \\
\hline $\begin{array}{l}\text { Konteks-Situasi } 4 \\
\text { Pada jam istirahat seperti biasa Anda jajan di kantin sekolah. Saat akan mem- } \\
\text { bayar makanan ternyata dompet Anda tertinggal di kelas. Anda ingin mem- } \\
\text { inta bantuan teman agar membayarkan dulu. Tuturan apa yang akan Anda } \\
\text { katakan kepada teman yang dimintai tolong ... }\end{array}$ \\
\hline
\end{tabular}

\section{CampurKode/AlihKode}

Kesantunan tuturan imperatif dipengaruhi juga oleh peristiwa campur kode atau alih kode dari penutur atau mitra tutur. Tuturan (RSP5-62) contoh 31 mengalami campur kode dengan penggunaan penanda kesantunan kata please. Tuturan (RSLL2159) contoh 32 mengalami alih kode dengan menggunaan bahasa Sunda "Baturan urang yuk ka warnet rek ngerjakeun tugas!". Tuturan (RSP6-93) contoh 33 mengalami campu kode dengan adanya klausa please help me dan tuturan (RSLL7-184) contoh 33 mengalami campur kode dengan menggunakan kata ganti orang atau kata sapaan Beb. Realisasi campur kode dan alih kode untuk menciptakan hubungan yang santai dan akrab sehingga meskipun mitra tutur dimintai tolong atau diperintah tetapi peristiwa tuturan diharapkan jarak sosial lebih dekat dan situasi tindak tutur menjadi akrab.

\begin{tabular}{|l|l|}
\hline (30) & $\begin{array}{l}\text { "Lia, antar aku ke warnet lah please! Aku ada tugas ... soalnya komputer aku } \\
\text { rusak." } \\
\text { (RSP5-62) } \\
\text { Responden siswa perempuan dengan mitra tutur siswa perempuan }\end{array}$ \\
\hline (31) & $\begin{array}{l}\text { "Baturan urang yuk ka warnet rek ngerjakeun tugas!" } \\
\text { (RSLL2-159) } \\
\text { Responden siswa laki-laki dengan mitra tutur siswa laki-laki }\end{array}$ \\
\hline
\end{tabular}




\begin{tabular}{|l|l|}
\hline & $\begin{array}{l}\text { Konteks-Situasi } 5 \\
\text { Anda mendapat tugas dari guru di sekolah. Untuk mencari data dan meny- } \\
\text { elesaikan tugas tersebut Anda harus pergi ke warnet karena computer di } \\
\text { rumah rusak dan ingin meminta tolong kepada teman untuk menemani ke } \\
\text { warnet. Tuturan apa yang akan Anda katakan kepada teman yang dimintai } \\
\text { tolong ... }\end{array}$ \\
\hline (32) & $\begin{array}{l}\text { "Indra bantuin dong, ambilin buku di lemari sana, please help me!" } \\
\text { RSP6-93) }\end{array}$ \\
\hline $\begin{array}{l}\text { Responden siswa perempuan dan mitra tutur siswa laki-laki } \\
\text { Anda mendapat tugas menjadi notulis dalam belajar kelompok yang diada- } \\
\text { kan di kelas. Saat itu Anda membutuhkan buku sebagai referensi dan ingin } \\
\text { meminta tolong kepada teman sekelompok. Tuturan apa yang akan Anda } \\
\text { katakan kepada teman yang dimintai tolong ... }\end{array}$ \\
\hline (33) & $\begin{array}{l}\text { "Beb, pinjem pulpen, soalnya tinta pulpen saya sudah habis." } \\
\text { (RSLL7-184) } \\
\text { Responden siswa laki-laki dengan mitra tutur siswa perempuan }\end{array}$ \\
\hline $\begin{array}{l}\text { Konteks-Situasi } 2 \\
\text { Anda sedang melaksanakan ulangan di kelas. Tiba-tiba pulpen yang diguna- } \\
\text { kan habis tintanya. Anda ingin meminjam kepada teman karena kalau mem- } \\
\text { beli ke koperasi khawatir lama dan waktu untuk menyelesaikan ujian ter- } \\
\text { ganggu. Tuturan apa yang akan Anda katakan kepada teman yang dimintai } \\
\text { tolong ... }\end{array}$ \\
\hline
\end{tabular}

\section{SIMPULAN}

Berdasarkan hasil penelitian yang dilakukan penulis diketahui bahwa kesantunan imperatif siswa perempuan lebih banyak diperlihatkan dengan strategi yang digunakan dalam bertutur imperatif. Jenis strategi yang digunakan mencapai 39 buah strategi; penanda verba 28 macam; penanda interjeksi 23 macam; jenis bentuk kalimat 20 macam; penanda pronomina 7 macam; penanda kesantunan 6 macam; dan campur kode/alih kode berjumlah 2 jenis.

Kesantunan imperatif siswa laki-laki pun lebih banyak diperlihatkan dengan strategi yang digunakan dalam bertutur imperatif. Jenis strategi yang digunakan mencapai 37 buah strategi; penanda verba 27 macam; penanda interjeksi 21 macam; jenis bentuk kalimat 13macam; penanda pronomina 13 macam; penanda kesantunan 13 macam; dan campur kode/alih kode berjumlah 9 jenis.

Dengan demikian, dapat disimpulkan bahwa strategi merupakan bentuk kesantunan imperatif siswa SMK di Bandung. Beragamnya strategi yang digunakan menjadi cara untuk menghargai mitra tutur sehingga terjalin komunikasi yang baik. 


\section{Daftar Pustaka}

Alisjahbana, S. Takdir. 1978. Tata Baru Bahasa Indonesia. Jakarta: Dian Rakyat.

Azis, E. Aminudin. 2003. "Usia dan Realisasi kesantunan Berbahasa: Sebuah Studi Pragmatik Para Penutur Bahasa Indonesia" makalah dalam PELBA 16. Jakarta: Yayasan Obor Indonesia.

Amir, Amil. 2004. "Pembelajaran Kesantunan Berbahasa" dalam Jurnal bahasa dan Seni Volume 3. Padang: Fakultas Sains dan Seni Universitas Negeri Padang.

Asri, Kurniati Wahyu \& Azizah Laelati. 2007. "Bias Jender dalam Perbedaan Penggunaan Bahasa oleh Laki-laki dan Perempuan". Kumpulan Makalah Ringkas Kongres Linguistik nasional XII. Jakarta: Universitas Sebelas Maret.

Brown, Gillian and George Yule. 1985. Discourse Analysis. Cambridge: Cambridge University Press.

Brown, Penelope and S.C. Levinson. 1987. 'Universal in Language usage: Politeness phenomena', dalam Estther N. Goody (ed.) Questions and Politeness. Cambridge: Cambridge University Press.

Chaer, A \& Leonie Agustina. 2005. Sosiolinguistik Perkenalan Awal. Jakarta: Rineka Cipta.

Djajasudarma, T. Fatimah. 1993. Metode Linguistik, Ancangan Metode Penelitian dan Kajian. Bandung: PT Eresco.

Fakih, Mansour. 2004. Analisis Gender dan Transformasi Sosial. Yogyakarta: Pustaka Pelajar.

Kaswanti Purwo, Bambang. 1987. "Pragmatik dan Linguistik" dalam Bacaan Linguistik . Yogyakarta: Masyarakat Linguistik Indonesia Komisariat Universitas Gajah Mada.

Kridalaksana, Harimurti. 1985. Fungsi Bahasa dan Sikap Bahasa. Ende: Nusa Indah.

Leech, Geoffrey N. 1983. Principles of Pragmatics. London: Longman.

Moeliono, Anton M. 1992a. Santun Bahasa. Jakarta: Penerbit PT Gramedia Pustaka Utama.

Moeliono, Anton M. 1992b. Tata Bahasa baku Bahasa Indonesia. Jakarta: Balai Pustaka.

Nadar, F.X. 2009. Pragmatik \&Penelitian Pragmatik. Yogyakarta: Graha IImu.

Rahardi, R. Kunjana. 2005. Pragmatik Kesantunan Imperatif Bahasa Indonesia. Jakarta: Erlangga.

Parera, Jos Daniel. 1987. Linguitik Edukasional: Pendekatan, Konsep, dan Teori Pengajaran Bahasa. Jakarta: Erlangga.

Searle, John R. 1975. 'Indirect speech acts', dalam P. Cole and J. Morgan (ed). Syntax and Semantics. Vol. 3: Speech Act. New York: Academic Press.

Sebeok, Thomas A (ed). 1978. Style in Language. Cambridge: The M.I.T. Press.

Sifianou, Maria. 1992. Polittness Phenomena in England and Greece, A CrossCultural Perpective. Oxford: Clarendon Press.

Subroto, Edi. 1992. Pengantar Metoda Penelitian Linguistik Struktural. Surakarta: Sebelas Maret University Press.

Sudaryanto. 1993. Metode dan Aneka Teknik Analisis Bahasa, Pengantar Penelitian Wahana Kebudayaan secara Linguistik. Yogyakarta: Duta Wacana University Press. 
Kesantunan Tuturan Imperatif Siswa SMK Muhammadiyah 2 Bandung:.....

Tarigan, Henry Guntur. 1990. Pengajaran Pragmatik. Bandung: Penerbit Angkasa.

Wijana, I Dewa Putu. 1996. Dasar-Dasar Pragmatik. Yogyakarta: Penerbit Andi.

Yule, George. 2000. Pragmatics. New York: Oxford University Press

46 | Ranah Volume 4 Nomor 1 Juli 2015 